\title{
State of the Art Survey of Deep Learning and Machine Learning Models for Smart Cities and Urban Sustainability
}

\author{
Saeed Nosratabadi ${ }^{1}(\mathbb{D})$, Amir Mosavi $^{2,3(\bowtie)}(\mathbb{D})$ Ramin Keivani $^{2}(\mathbb{D}$, \\ Sina Ardabili ${ }^{4}$ (D), and Farshid Aram ${ }^{5}$ \\ ${ }^{1}$ Institute of Business Studies, Szent Istvan University, Godollo 2100, Hungary \\ ${ }^{2}$ School of the Built Environment, Oxford Brookes University, Oxford, UK \\ amir.mosavi@kvk.uni-obuda.hu \\ ${ }^{3}$ Kalman Kando Faculty of Electrical Engineering, Obuda University, \\ Budapest, Hungary \\ ${ }^{4}$ Institute of Advanced Studies Koszeg, Koszeg, Hungary \\ 5 Escuela Técnica Superior de Arquitectura, Universidad \\ Politécnica de Madrid-UPM, 28040 Madrid, Spain
}

\begin{abstract}
Deep learning (DL) and machine learning (ML) methods have recently contributed to the advancement of models in the various aspects of prediction, planning, and uncertainty analysis of smart cities and urban development. This paper presents the state of the art of DL and ML methods used in this realm. Through a novel taxonomy, the advances in model development and new application domains in urban sustainability and smart cities are presented. Findings reveal that five DL and ML methods have been most applied to address the different aspects of smart cities. These are artificial neural networks; support vector machines; decision trees; ensembles, Bayesians, hybrids, and neurofuzzy; and deep learning. It is also disclosed that energy, health, and urban transport are the main domains of smart cities that DL and ML methods contributed in to address their problems.
\end{abstract}

Keywords: Deep learning $\cdot$ Machine learning $\cdot$ Smart cities $\cdot$

Urban sustainability $\cdot$ Cities of future $\cdot$ Internet of things (IoT) - Data science Big data

\section{Introduction}

Global urbanization is growing at a fast pace [1]. In the near future, major population of the world will be moving to the cities [2]. This trend will be extremely challenging for the land use management, sustainable urban development, food supply, safety, security, and human well-being in general [3, 4].

The emerging technologies and novel concepts for smart cities have been very promising to encourage a brighter future in dealing with the cities of the future. The artificial intelligence applications such as internet of things (IoT) [5], machine learning (ML) [6-9], deep learning (DL) [10] and big data [7, 11-15], have been essential in supporting the smart cities evolution and technological advancement. Among them, 
ML methods have been contributing to various application domains with promising results in, e.g., mobility management and monitoring, city planning, resource allocation, energy demand and consumption prediction, food supply and production prediction, air pollution monitoring and prediction, etc. [16-21].

Literature includes an adequate number of state of the art review papers and comparative analysis on the general applications of ML and DL methods [22-35]. The trends of the advancement of ML and DL methods are reported to be hybrid and ensemble methods [36-46]. Considering the smart cities research, although, there have been various surveys on the applications of artificial intelligence, ML and DL methods, an insight into the popular methods, classification of the methods, and future trend in the advancement of novel methods are not given yet [47-54]. Thus, the current research aims to fill this gap through providing the state-of-the-art of ML and DL methods used for smart cities toward a more sustainable approach for urban sustainability. To do so, a novel classification is used to identify the most popular ML and DL models and review them in individual groups according to the methods used. This paper further contributes to identifying future trends in the advancement of learning algorithms for smart cities. Unlike in other fields, e.g., atmospheric sciences and hydrology were hybrids, and ensemble ML models have increased in popularity, in the smart city domain DL applications are dominant.

\section{ML and DL Models for Smart Cities}

To identify the most relevant literature in the realm of using ML and DL methods for smart cities and sustainable urban development we explored the web of science (WoS) and Scopus with the following search keywords: "smart cities" or "sustainable urban development" and all the existing ML and DL methods [12]. Figure 1 represents the overall research results showing the exponential growth in using the ML and DL methods for smart cities and sustainable urban development. The search in the major

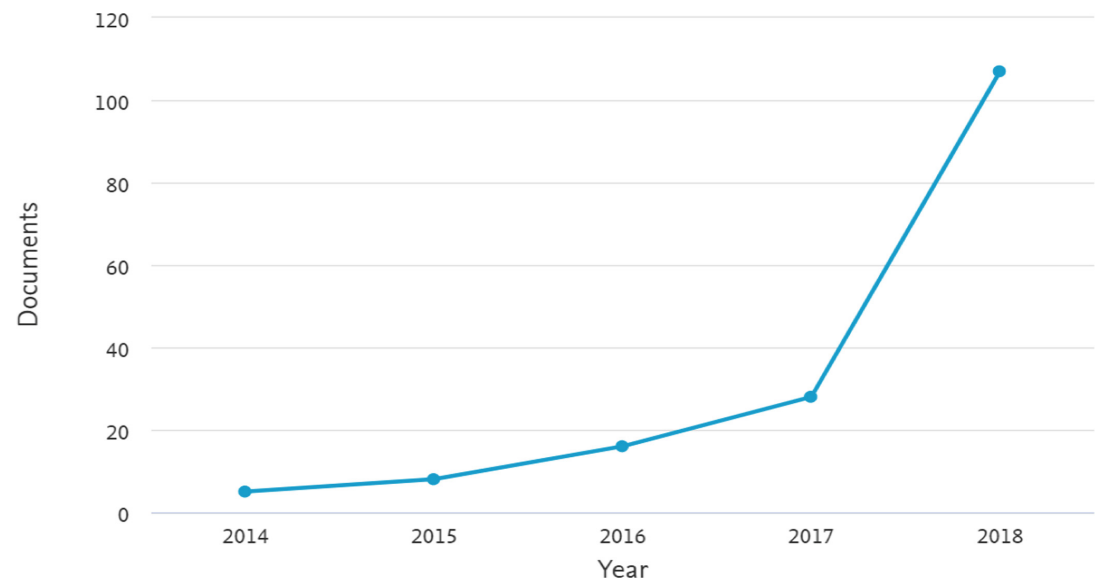

Fig. 1. The exponential growth in using ML and DL methods for smart cities and sustainable urban development (source: web of science) 
research databases revealed that the popularity of machine learning is still limited in only a handful of ML and DL methods.

In the following the popular ML and DL methods are identified and reviewed in the classified tables based on the methods used.

\subsection{Artificial Neural Networks in Smart Cities}

As it is summarized in Table 1, several research papers have applied artificial neural networks (ANNs) in the context of smart cities. ANNs have many applications in smart cities, including hazard detection, water supply, energy, and urban transport. Ullah et al. [55], for instance, develop infrastructures for smart lightning detection system aided by ANNs. Yuan et al. [56] provide an approach to improve the stability of wind turbines in smart cities. Rojek and Studzinski [57] design a method to detect water leaks in smart cities utilizing neural networks. Pan et al. [58] and Vlahogianni et al. [59] have applied ANNs to provide solutions for urban transport in smart cities.

Table 1. Notable applications and contributions of ANNs in the smart cities

\begin{tabular}{l|l|l}
\hline $\begin{array}{l}\text { Literature } \\
\text { references }\end{array}$ & Contributions & $\begin{array}{l}\text { Application } \\
\text { domains }\end{array}$ \\
\hline Ullah et al. [55] & $\begin{array}{l}\text { Utilizing artificial neural network to develop } \\
\text { Infrastructures for the smart lightning detection } \\
\text { system }\end{array}$ & $\begin{array}{l}\text { Hazard } \\
\text { detection }\end{array}$ \\
\hline Yuan et al. [56] & Increasing the stability of wind turbines in smart cities & Energy \\
\hline $\begin{array}{l}\text { Rojek and } \\
\text { Studzinski [57] }\end{array}$ & $\begin{array}{l}\text { Providing a solution for water leaks detection } \\
\text { utilizing neural networks in smart cities }\end{array}$ & $\begin{array}{l}\text { Water supply } \\
\text { and energy }\end{array}$ \\
\hline Pan et al. [58] & $\begin{array}{l}\text { Network traffic prediction for the smart cities using } \\
\text { DE-BP neural network }\end{array}$ & $\begin{array}{l}\text { Urban } \\
\text { transport }\end{array}$ \\
\hline $\begin{array}{l}\text { Vlahogianni et al. } \\
\text { [59] }\end{array}$ & $\begin{array}{l}\text { Developing a prediction system for real-time parking } \\
\text { in smart cities }\end{array}$ & $\begin{array}{l}\text { Urban } \\
\text { transport }\end{array}$ \\
\hline
\end{tabular}

\subsection{Support Vector Machines}

Support vector machines (SVMs) is another machine learning method that can be used to deal with smart cities' problems. SVMs have been applied in different aspects of a smart city such as water supply, Energy, evaluation and management of smart, and health domains. Table 2 elaborates the contribution and domain application of SVMs in the smart cities, where Livingston et al. [60] provide solutions to improve water utilization in smart cities utilizing SVM. Chen and Zhang [61] providing a model to evaluate green smart cities in China. Chui et al. [62] propose an innovative approach to evaluate energy sustainability in smart cities. Ultimately, Aborokbah et al. [63] and Muhammad et al. [64] utilize SVMs to provide solutions for the health industry of smart cities. 
Table 2. Notable applications and contributions of SVMs in the smart cities

\begin{tabular}{l|l|l}
\hline Literature references & Contributions & $\begin{array}{l}\text { Application } \\
\text { domains }\end{array}$ \\
\hline Livingston et al. [60] & $\begin{array}{l}\text { Improving water utilization in smart cities } \\
\text { using SVM }\end{array}$ & Water supply \\
\hline Chen and Zhang [61] & $\begin{array}{l}\text { Providing a model to assess green smart } \\
\text { cities in China }\end{array}$ & $\begin{array}{l}\text { Evaluation and } \\
\text { management of } \\
\text { smart cities }\end{array}$ \\
\hline Chui et al. [62] & $\begin{array}{l}\text { Proposing a novel approach to evaluate } \\
\text { energy sustainability in smart cities }\end{array}$ & Energy \\
\hline Aborokbah et al. [63] & $\begin{array}{l}\text { Designing an adaptive context-aware } \\
\text { decision computing paradigm for intensive } \\
\text { health care delivery in smart cities }\end{array}$ & Health \\
\hline Muhammad et al. [64] & $\begin{array}{l}\text { Designing a facial-expression monitoring } \\
\text { system to improve healthcare in smart cities }\end{array}$ & Health \\
\hline
\end{tabular}

\subsection{Tree-Based Models (Decision Trees)}

Another ML method which has been applied to solve problems of different aspects of smart cities is Decision trees (DTs) method. As it is detailed in Table 3, researchers have applied DTs to address the issues related to businesses, air pollution, urban transport, and food to develop a smart city. Ilapakurti et al. [65] formulate adaptive edge analytics for creating a memorable customer experience and venue brand engagement for smart cities. Orlowski et al. [66] design business models to measure air quality for smart cities for using IoT (Internet of Things) and SaaS (software as a service). Mei et al. [67] design an incentive framework for an intelligent traffic system based on initiative game-theory. Vuppalapati et al. [68] design a smart dairy model using IoT sensor network measuring cattle's health issues, milk production prediction, and productivity improvement.

Table 3. Notable applications and contributions of Decision trees in the smart cities

\begin{tabular}{l|l|l}
\hline $\begin{array}{l}\text { Literature } \\
\text { references }\end{array}$ & Contributions & $\begin{array}{l}\text { Application } \\
\text { domains }\end{array}$ \\
\hline $\begin{array}{l}\text { Ilapakurti } \\
\text { et al. [65] }\end{array}$ & $\begin{array}{l}\text { Formulating adaptive edge analytics for creating a } \\
\text { memorable customer experience and venue brand } \\
\text { engagement for smart cities }\end{array}$ & Businesses \\
\hline $\begin{array}{l}\text { Orlowski } \\
\text { et al. [66] }\end{array}$ & $\begin{array}{l}\text { Designing business models to measure air quality for smart } \\
\text { cities for using IoT (Internet of Things) and SaaS (Software } \\
\text { as a Service) }\end{array}$ & $\begin{array}{l}\text { Air } \\
\text { Pollution }\end{array}$ \\
\hline $\begin{array}{l}\text { Mei et al. } \\
\text { [67] }\end{array}$ & $\begin{array}{l}\text { Designing an incentive framework for an intelligent traffic } \\
\text { system based on initiative game-theory }\end{array}$ & $\begin{array}{l}\text { Urban } \\
\text { transport }\end{array}$ \\
\hline $\begin{array}{l}\text { Vuppalapati } \\
\text { et al. [68] }\end{array}$ & $\begin{array}{l}\text { Designing a smart dairy model using IoT sensor network } \\
\text { measuring cattle's health issues, milk production prediction } \\
\text { and productivity improvement }\end{array}$ & Food \\
\hline
\end{tabular}




\subsection{Ensembles, Bayesian, Hybrids, and Neuro-Fuzzy}

In addition to ANNs, SVMs, and DTs, which have a remarkable contribution to smart cities; ensembles, Bayesian, hybrids, and neuro-fuzzy have been applied to address the issues in the domains such as energy, urban governance, evaluation and management of smart cities, and health for smart cities. Table 4 summarizes the articles that have used ensembles, Bayesian, hybrids, and neuro-fuzzy to deal with different problems in smart cities. Where Nguyen et al. [69] design a sustainable model for urban landscape evolution city. Taveres-Cachat et al. [70] propose a framework to build a zero-emission neighborhood using responsive building envelope. Ju et al. [71] design a framework to apply citizen-centered big data for governance intelligence in smart cities. Tan et al. [72] develop an adaptive neuro-fuzzy inference system approach for urban sustainability assessment. Finally, Sajjad et al. [73] provide a quality computer-aided blood analysis system to discover and count the white blood cells in blood samples. Their approach contributes to making the healthcare industry smart in the smart city (see Table 4).

Table 4. Notable applications and contributions of ensembles, Bayesian, hybrids, and neurofuzzy in the smart cities

\begin{tabular}{|c|c|c|}
\hline $\begin{array}{l}\text { Literature } \\
\text { references }\end{array}$ & Contributions & Application domains \\
\hline Nguyen et al. [69] & $\begin{array}{l}\text { Designing a sustainable model for urban } \\
\text { landscape evolution city }\end{array}$ & $\begin{array}{l}\text { Evaluation and } \\
\text { management of } \\
\text { smart cities }\end{array}$ \\
\hline $\begin{array}{l}\text { Taveres-Cachat } \\
\text { et al. [70] }\end{array}$ & $\begin{array}{l}\text { Designing a framework to build a zero- } \\
\text { emission neighborhood using responsive } \\
\text { building envelope }\end{array}$ & Energy \\
\hline Ju et al. [71] & $\begin{array}{l}\text { Proposing a framework to apply citizen- } \\
\text { centered big data for governance intelligence } \\
\text { in smart cities }\end{array}$ & $\begin{array}{l}\text { Evaluation and } \\
\text { management of } \\
\text { smart cities }\end{array}$ \\
\hline Tan et al. [72] & $\begin{array}{l}\text { Developing an adaptive neuro-fuzzy inference } \\
\text { system approach for urban sustainability } \\
\text { assessment }\end{array}$ & $\begin{array}{l}\text { Evaluation and } \\
\text { management of } \\
\text { smart cities }\end{array}$ \\
\hline Sajjad et al. [73] & $\begin{array}{l}\text { Providing a quality computer-aided blood } \\
\text { analysis system to the discover and count the } \\
\text { white blood cells in blood samples }\end{array}$ & Health \\
\hline
\end{tabular}

\subsection{Deep Learning}

Deep learning methods have had numerous and various applications in developing smart cities. The body of research, aided by such methods, has contributed to different aspects of a smart city such as energy sector, health, transportation, and even management of smart cities. As it is presented in Table 5, Luo et al. [74] and VázquezCanteli et al. [75] utilize deep learning to provide solutions in the energy sector for the smart cities. Where Luo et al. [74] design a system for a short-term energy prediction 
for a smart city. Vázquez-Canteli et al. [75] develop an integrated simulation environment to manage energy intelligently. Baba et al. [76] provide a sensor network for violence detection in smart cities. Reddy and Mehta [77] propose a system for smart traffic management for smart cities. Muhammed et al. [48] and Obinikpo and Kantarci [78] applied deep learning to deal with the concerns in the health sector. Finally, Madu et al. [79] propose a framework to evaluate urban sustainability utilizing deep learning.

Table 5. Notable applications and contributions of deep learning in the smart cities

\begin{tabular}{l|l|l}
\hline $\begin{array}{l}\text { Literature } \\
\text { references }\end{array}$ & Contributions & Application domains \\
\hline Luo et al. [74] & $\begin{array}{l}\text { Crafting a system for a short-term energy } \\
\text { prediction for smart city }\end{array}$ & Energy \\
\hline Baba et al. [76] & $\begin{array}{l}\text { Designing a sensor network for violence } \\
\text { detection in smart cities }\end{array}$ & Security \\
\hline $\begin{array}{l}\text { Reddy and Mehta } \\
\text { [77] }\end{array}$ & $\begin{array}{l}\text { Proposing a system for Smart traffic } \\
\text { management in smart cities utilizing } \\
\text { reinforcement learning algorithm }\end{array}$ & Urban transport \\
\hline $\begin{array}{l}\text { Vázquez-Canteli } \\
\text { et al. [75] }\end{array}$ & $\begin{array}{l}\text { Developing an integrated simulation } \\
\text { environment to manage energy intelligently in } \\
\text { smart cities }\end{array}$ & Energy \\
\hline $\begin{array}{l}\text { Muhammed et al. } \\
\text { [48] }\end{array}$ & $\begin{array}{l}\text { Providing a ubiquitous healthcare framework, } \\
\text { utilizing edge computing, deep learning, big } \\
\text { data, high-performance computing (HPC), and } \\
\text { the Internet of Things (IoT) }\end{array}$ & Health \\
\hline $\begin{array}{l}\text { Obinikpo and } \\
\text { Kantarci [78] }\end{array}$ & $\begin{array}{l}\text { Providing all the applications of deep learning } \\
\text { methods used in sensed data for prediction in } \\
\text { smart health services }\end{array}$ & Health \\
\hline Madu et al. [79] & $\begin{array}{l}\text { Providing a framework to evaluate urban } \\
\text { sustainability utilizing deep learning }\end{array}$ & $\begin{array}{l}\text { Evaluation and } \\
\text { management of } \\
\text { smart cities }\end{array}$ \\
\hline
\end{tabular}

\section{Discussion and Conclusions}

The current paper provided a comprehensive state-of-the-art of ML and DL methods used for smart cities toward urban sustainability. A novel classification is used to identify the most popular ML and DL model and review them in individual groups according to the methods used. The ANNs, SVMs, DTs, Ensembles, Bayesians, and neuro-fuzzy methods have been seen as the most used machine learning methods. The finding revealed that ML and DL methods had remarkable contributions to the development of smart cities. It is also shown that energy, health, urban transport, evaluation and management of smart cities, water supply, businesses, air pollution, food, urban governance, security, and hazard detection are different domains of smart cities have borrowed ML and DL methods to deal with the similar problems. 
Energy was the sector which has most leveraged the ML and DL methods in development of smart cities as four out of the 5 methods concerned in this study (artificial neural networks, support vector machines (SVMs), Ensembles, Bayesians, hybrids, and neuro-fuzzy, deep learning) are applied to provide different solutions for this sector. After energy, health, urban transport, and evaluation and management of smart cities are the other smart cities domains that have had most attention by the researchers in the standard fields of ML and DL methods and smart cities where at least three different ML and DL methods are applied to address their research questions. This paper also reveals an unexpected result, i.e., the immense popularity of DL methods. The DL methods have been seen dramatically popular in smart city applications mainly published in 2018 and 2019. This paper further identified future trends in the advancement of learning algorithms for smart cities. The trend in smart cities have shown to follow the trend in the overall trend which is a shift toward the advancement of the more sophisticated hybrid, ensemble and deep learning models, as also shown in [80-88].

\section{References}

1. Haase, D., et al. Global Urbanization. In: The Urban Planet: Knowledge Towards Sustainable Cities, vol. 19 (2018)

2. Galea, S., Ettman, C.K., Vlahov, D.: The Present and Future of Cities. Urban Health, p. 1 (2019)

3. Wang, S.J., Moriarty, P.: Urban health and well-being challenges. In: Big Data for Urban Sustainability, pp. 23-43. Springer (2018)

4. Nosratabadi, S., et al.: Sustainable business models: a review. Sustainability 11(6), 1663 (2019)

5. Alavi, A.H., et al.: Internet of Things-enabled smart cities: state-of-the-art and future trends. Measurement 129, 589-606 (2018)

6. Dineva, A., et al.: Review of soft computing models in design and control of rotating electrical machines. Energies 12(6) (2019)

7. Ghalandari, M., et al.: Investigation of submerged structures' flexibility on sloshing frequency using a boundary element method and finite element analysis. Eng. Appl. Comput. Fluid Mech. 13(1), 519-528 (2019)

8. Qasem, S.N., et al.: Estimating daily dew point temperature using machine learning algorithms. Water (Switzerland) 11(3) (2019)

9. Taherei Ghazvinei, P., et al.: Sugarcane growth prediction based on meteorological parameters using extreme learning machine and artificial neural network. Eng. Appl. Comput. Fluid Mech. 12(1), 738-749 (2018)

10. Vargas, R., Mosavi, A., Ruiz, R.: Deep learning: a review. In: Advances in Intelligent Systems and Computing (2017)

11. Mosavi, A., Lopez, A., Varkonyi-Koczy, A.R.: Industrial applications of big data: state of the art survey. In: Luca, D., Sirghi, L., Costin, C. (eds.), pp. 225-232. Springer (2018)

12. Mosavi, A., Ozturk, P., Chau, K.W.: Flood prediction using machine learning models: literature review. Water (Switzerland) 10(11) (2018)

13. Mosavi, A,. Rabczuk, T.: Learning and intelligent optimization for material design innovation. In: Kvasov, D.E., et al. (eds.), pp. 358-363. Springer (2017) 
14. Mosavi, A., Varkonyi-Koczy, A.R.: Integration of machine learning and optimization for robot learning. In: Jablonski, R., Szewczyk, R. (eds.), pp. 349-355. Springer (2017)

15. Torabi, M., et al.: A Hybrid clustering and classification technique for forecasting short-term energy consumption. Environ. Prog. Sustain. Energy 38(1), 66-76 (2019)

16. Audu, A.R.A., et al.: An intelligent predictive analytics system for transportation analytics on open data towards the development of a smart city. In: Hussain, F.K., Barolli, L., Ikeda, M. (eds.) pp. 224-236. Springer (2020)

17. Rebelo, F., Noriega, P., Oliveira, T.: Evaluation of the concept of a smart city gamification from a user centered design perspective. In: Soares, M.M., Rebelo, F. (eds.), pp. 207-219. Springer (2020)

18. Ruzina, E.I.: From information city to smart city: Russian experience of state entrepreneurship. In: Solovev, D.B. (ed.), pp. 419-430. Springer Science and Business Media Deutschland GmbH (2020)

19. Sharifi, A.: A critical review of selected smart city assessment tools and indicator sets. J. Clean. Prod. 233, 1269-1283 (2019)

20. Valdeolmillos, D., Mezquita, Y., Ludeiro, A.R.: Sensing as a service: An architecture proposal for big data environments in smart cities. In: Novais, P., et al. (eds.), pp. 97-104. Springer (2020)

21. Wataya, E., Shaw, R.: Measuring the value and the role of soft assets in smart city development. Cities 94, 106-115 (2019)

22. Aram, F., et al.: Design and validation of a computational program for analysing mental maps: Aram mental map analyzer. Sustainability (Switzerland) 11(14) (2019)

23. Asadi, E., et al.: Groundwater quality assessment for drinking and agricultural purposes in Tabriz Aquifer, Iran (2019)

24. Asghar, M.Z., Subhan, F., Imran, M., Kundi, F.M., Shamshirband, S., Mosavi, A., Csiba, P., Várkonyi-Kóczy, A.R.: Performance evaluation of supervised machine learning techniques for efficient detection of emotions from online content (2019), 2019080019. https://doi.org/ 10.20944/preprints201908.0019.v1

25. Bemani, A., Baghban, A., Shamshirband, S., Mosavi, A., Csiba, P., Várkonyi-Kóczy, A.R.: Applying ANN, ANFIS, and LSSVM models for estimation of acid solvent solubility in supercritical CO2. (2019), 2019060055. https://doi.org/10.20944/preprints201906.0055.v2

26. Choubin, B., et al.: Snow avalanche hazard prediction using machine learning methods. J. Hydrol. 577 (2019)

27. Choubin, B., et al.: An ensemble prediction of flood susceptibility using multivariate discriminant analysis, classification and regression trees, and support vector machines. Sci. Total Environ. 651, 2087-2096 (2019)

28. Dehghani, M., et al.: Prediction of hydropower generation using Grey wolf optimization adaptive neuro-fuzzy inference system. Energies 12(2) (2019)

29. Dineva, A., et al.: Multi-label classification for fault diagnosis of rotating electrical machines (2019)

30. Farzaneh-Gord, M., et al.: Numerical simulation of pressure pulsation effects of a snubber in a CNG station for increasing measurement accuracy. Eng. Appl. Comput. Fluid Mech. 13(1), 642-663 (2019)

31. Ghalandari, M., et al.: Flutter speed estimation using presented differential quadrature method formulation. Eng. Appl. Comput. Fluid Mech. 13(1), 804-810 (2019)

32. Karballaeezadeh, N., et al.: Prediction of remaining service life of pavement using an optimized support vector machine (case study of Semnan-Firuzkuh road). Eng. Appl. Comput. Fluid Mech. 13(1), 188-198 (2019) 
33. Menad, N.A., et al.: Modeling temperature dependency of oil - water relative permeability in thermal enhanced oil recovery processes using group method of data handling and gene expression programming. Eng. Appl. Comput. Fluid Mech. 13(1), 724-743 (2019)

34. Mohammadzadeh, S., et al.: Prediction of compression index of fine-grained soils using a gene expression programming model. Infrastructures 4(2), 26 (2019)

35. Mosavi, A., Edalatifar, M.: A hybrid neuro-fuzzy algorithm for prediction of reference evapotranspiration. in Lecture Notes in Networks and Systems, pp. 235-243. Springer (2019)

36. Mosavi, A., Rabczuk, T., Varkonyi-Koczy, A.R.: Reviewing the novel machine learning tools for materials design. In: Luca, D., Sirghi, L., Costin, C. (eds.), pp. 50-58. Springer (2018)

37. Mosavi, A., et al.: State of the art of machine learning models in energy systems, a systematic review. Energies 12(7) (2019)

38. Mosavi, A., et al.: Prediction of multi-inputs bubble column reactor using a novel hybrid model of computational fluid dynamics and machine learning. Eng. Appl. Comput. Fluid Mech. 13(1), 482-492 (2019)

39. Nosratabadi, S., et al.: Sustainable business models: a review. Sustainability (Switzerland) 11(6) (2019)

40. Rezakazemi, M., Mosavi, A., Shirazian, S.: ANFIS pattern for molecular membranes separation optimization. J. Mol. Liq. 274, 470-476 (2019)

41. Riahi-Madvar, H., et al.: Comparative analysis of soft computing techniques RBF, MLP, and ANFIS with MLR and MNLR for predicting grade-control scour hole geometry. Eng. Appl. Comput. Fluid Mech. 13(1), 529-550 (2019)

42. Shabani, S., Samadianfard, S., Taghi Sattari, M., Shamshirband, S., Mosavi, A., Kmet, T., Várkonyi-Kóczy, A.R.: Modeling daily pan evaporation in humid cli-mates using gaussian process regression (2019), 2019070351. https://doi.org/10.20944/preprints201907.0351.v1

43. Shamshirband, S., Hadipoor, M., Baghban, A., Mosavi, A., Bukor J., Varkonyi-Koczy, A. R.: Developing an ANFIS-PSO model to predict mercury emissions in combustion flue gases (2019), 2019070165. https://doi.org/10.20944/preprints201907.0165.v1

44. Shamshirband, S., et al.: Ensemble models with uncertainty analysis for multi-day ahead forecasting of chlorophyll a concentration in coastal waters. Eng. App. Comput. Fluid Mech. 13(1), 91-101 (2019)

45. Shamshirband, S., Mosavi, A., Rabczuk, T.: Particle swarm optimization model to predict scour depth around bridge pier (2019). arXiv:1906.08863

46. Torabi, M., et al.: A hybrid machine learning approach for daily prediction of solar radiation. In: Lecture Notes in Networks and Systems, pp. 266-274. Springer (2019)

47. de Souza, J.T., et al.: Data mining and machine learning to promote smart cities: a systematic review from 2000 to 2018. Sustainability (Switzerland) 11(4) (2019)

48. Muhammed, T., et al.: UbeHealth: A personalized ubiquitous cloud and edge-enabled networked healthcare system for smart cities. IEEE Access 6, 32258-32285 (2018)

49. Nagy, A.M., Simon, V.: Survey on traffic prediction in smart cities. Pervasive Mobile Comput. 50, 148-163 (2018)

50. O'Dwyer, E., et al.: Smart energy systems for sustainable smart cities: current developments, trends and future directions. Appl. Energy 581-597 (2019)

51. Soomro, K., et al.: Smart city big data analytics: An advanced review. In: Data Mining and Knowledge Discovery. Wiley Interdisciplinary Reviews (2019)

52. Usman, M., et al.: A survey on big multimedia data processing and management in smart cities. ACM Comput. Surv. 52(3) (2019)

53. Zhao, L., et al.: Routing for crowd management in smart cities: A deep reinforcement learning perspective. IEEE Commun. Mag. 57(4), 88-93 (2019) 
54. Aram, F., et al.: Design and validation of a computational program for analysing mental maps: aram mental map analyzer. Sustainability 11(14), 3790 (2019)

55. Ullah, I., et al.: Smart lightning detection system for smart-city infrastructure using artificial neural network. Wirel. Pers. Commun. 106(4), 1743-1766 (2019)

56. Yuan, Z., Wang, W., Fan, X.: Back propagation neural network clustering architecture for stability enhancement and harmonic suppression in wind turbines for smart cities. Comput. Electr. Eng. 74, 105-116 (2019)

57. Rojek, I., Studzinski, J.: Detection and localization of water leaks in water nets supported by an ICT system with artificial intelligence methods as away forward for smart cities. Sustainability (Switzerland) 11(2) (2019)

58. Pan, X., et al.: Prediction of network traffic of smart cities based on DE-BP neural network. IEEE Access 7, 55807-55816 (2019)

59. Vlahogianni, E.I., et al.: A real-time parking prediction system for smart cities. J. Intell. Trans. Syst. Technol. Plan. Oper. 20(2), 192-204 (2016)

60. Livingston, S.J., et al.: A hybrid approach for water utilization in smart cities using machine learning techniques. Int. J. Innov. Technol. Explor. Eng. 8(6), 488-493 (2019)

61. Chen, L., Zhang, H.: Evaluation of green smart cities in china based on entropy weight-cloud model. Xitong Fangzhen Xuebao/J Syst Simul. 31(1), 136-144 (2019)

62. Chui, K.T., Lytras, M.D., Visvizi, A.: Energy sustainability in smart cities: artificial intelligence, smart monitoring, and optimization of energy consumption. Energies 11(11) (2018)

63. Aborokbah, M.M., et al.: Adaptive context aware decision computing paradigm for intensive health care delivery in smart cities-A case analysis. Sustain. Cities Soc. 41, 919-924 (2018)

64. Muhammad, G., et al.: A facial-expression monitoring system for improved healthcare in smart cities. IEEE Access 5, 10871-10881 (2017)

65. Ilapakurti, A., et al.: Adaptive edge analytics for creating memorable customer experience and venue brand engagement, a scented case for Smart Cities. Institute of Electrical and Electronics Engineers Inc. (2018)

66. Orlowski, C., et al.: Decision processes based on IoT data for sustainable smart cities. In: Lecture Notes in Computer Science (including subseries Lecture Notes in Artificial Intelligence and Lecture Notes in Bioinformatics), pp. 136-146. Springer (2018)

67. Mei, H., Poslad, S., Du, S.: A game-theory based incentive framework for an intelligent traffic system as part of a smart city initiative. Sensors (Switzerland) 17(12) (2017)

68. Vuppalapati, J.S., et al.: Smart dairies-enablement of smart city at gross root level. Institute of Electrical and Electronics Engineers Inc. (2017)

69. Nguyen, T.A., et al.: Toward a sustainable city of tomorrow: a hybrid Markov-Cellular Automata modeling for urban landscape evolution in the Hanoi city (Vietnam) during 19902030. Environ. Dev. Sustain. 21(1), 429-446 (2019)

70. Taveres-Cachat, E., et al.: Responsive building envelope concepts in zero emission neighborhoods and smart cities-a roadmap to implementation. Build. Environ. 149, 446-457 (2019)

71. Ju, J., Liu, L., Feng, Y.: Citizen-centered big data analysis-driven governance intelligence framework for smart cities. Telecommun. Policy 42(10), 881-896 (2018)

72. Tan, Y., et al.: Adaptive neuro-fuzzy inference system approach for urban sustainability assessment: a China case study. Sustain. Dev. 26(6), 749-764 (2018)

73. Sajjad, M., et al.: Leukocytes classification and segmentation in microscopic blood smear: a resource-aware healthcare service in smart cities. IEEE Access 5, 3475-3489 (2017)

74. Luo, H., et al.: A short-term energy prediction system based on edge computing for smart city. Future Gener. Comput. Syst. 101, 444-457 (2019) 
75. Vázquez-Canteli, J.R., et al.: Fusing TensorFlow with building energy simulation for intelligent energy management in smart cities. Sustain. Cities Soc. 45, 243-257 (2019)

76. Baba, M., et al.: A sensor network approach for violence detection in smart cities using deep learning. Sensors (Switzerland) 19(7) (2019)

77. Reddy, D.V.S., Mehta, R.V.K.: Smart traffic management system for smart cities using reinforcement learning algorithm. Int. J. Recent Technol. Eng. 7(6), 12-15 (2019)

78. Obinikpo, A.A., Kantarci, B.: Big sensed data meets deep learning for smarter health care in smart cities. J. Sens. Actuator Netw. 6(4) (2017)

79. Madu, C.N., Kuei, C.H., Lee, P.: Urban sustainability management: A deep learning perspective. Sustain. Cities Soc. 30, 1-17 (2017)

80. Ardabili, S., Mosavi, A., Mahmoudi, Gundoshmian, T.M., Nosratabadi, S., VarkonyiKoczy, A.: Modelling temperature variation of mushroom growing hall using artificial neural networks (2019)

81. Gundoshmian, T.M., Ardabili, S., Mosavi, A., Varkonyi-Koczy, A., Prediction of combine harvester performance using hybrid machine learning modeling and response surface methodology (2019)

82. Ardabili, S., Mosavi, A., Varkonyi-Koczy, A.: Systematic review of deep learning and machine learning models in biofuels research (2019)

83. Ardabili, S., Mosavi, A., Varkonyi-Koczy, A., Advances in machine learning model-ing reviewing hybrid and ensemble methods (2019)

84. Ardabili, S., Mosavi, A., Varkonyi-Koczy, A.: Building Energy information: demand and consumption prediction with Machine Learning models for sustainable and smart cities (2019)

85. Ardabili, S., Mosavi, A., Dehghani, M., Varkonyi-Koczy, A.: Deep learning and machine learning in hydrological processes climate change and earth systems a systematic review (2019)

86. Mohammadzadeh D., Karballaeezadeh, N., Mohemmi, M., Mosavi, A., Varkonyi-Koczy A.: Urban train soil-structure interaction modeling and analysis (2019)

87. Mosavi, A., Ardabili, S., Varkonyi-Koczy, A., List of deep learning models (2019)

88. Nosratabadi, S., Mosavi, A., Keivani, R., Ardabili, S., Aram, F.: State of the art survey of deep learning and machine learning models for smart cities and urban sustainability (2019) 